\title{
Requirement of Whole-Genome Sequencing and Background History of the National and International Genome Initiatives
}

\author{
Mahendar Thudi and Rajeev K. Varshney
}

\begin{abstract}
Chickpea is the second most important grain legume for food and nutritional security in the arid and semi-arid regions of the world. The genome sequence provides the basis for a wide range of studies, from the important goal of accelerated breeding to identifying the molecular basis of key agronomic traits, in addition to understanding the basic legume biology. The discussions during 5th International Conference on Legume Genetics and Genomics, held during July 8-10, 2010 in Asilomar, USA, provided the platform for the genesis of International Chickpea Genome Sequencing Consortium (ICGSC http://ceg.icrisat.org/gt-bt/ICGGC/ ICGSC.htm), and as result of global research partnership co-led by ICRISAT, UC-Davis, and BGI-Shenzhen, involving 49 scientists from 23 organizations in 10 countries the draft genome of kabuli genotype CDC Frontier was published. On the other hand, the Next Generation Challenge Programme on Chickpea Genomics (NGCPCG) initiative unraveled the genome sequence of desi genotype ICC 4958. This chapter summarizes the background history of two independent efforts to generate draft genome sequence of kabuli and desi chickpea genomes. In addition, the chapter also highlights key developments of application of genome sequence for crop improvement.
\end{abstract}

M. Thudi $(\bowtie) \cdot$ R.K. Varshney International Crops Research Institute for the Semi-Arid Tropics (ICRISAT), Patancheru PO 502324, India

e-mail: t.mahendar@cgiar.org

\subsection{Introduction}

The genus Cicer is a member of the monogeneric tribe Cicereae Alef; subfamily Papilionaceae, family Leguminosae, which includes 9 annual and 34 perennial species (van der Maesen 1987). Chickpea ( $C$. arietinum L.) is the only Cicer species cultivated on a large scale, self-pollinated diploid $(2 n=2 x=16)$ with a genome size 
of $\sim 740 \mathrm{Mbp}$ (Arumuganathan and Earle 1991). It is the second most important pulse crop in the world covering an area of 13.9 mha (FAO 2016). Two distinct chickpea types, different in their morphology and used in different ways of processing have been described: desi and kabuli. Desi-type chickpeas have purple flower and small, dark, and angular seeds; it is largely consumed in India and Pakistan. Kabuli chickpeas have white flower and large, cream-colored seeds; it is preferred in the Mediterranean Basin and Central Asia, mainly consumed as whole seed. The kabuli type constitutes only $\sim 15 \%$ of global chickpea production, but good quality large-seeded kabuli chickpea are very much appreciated in the market and fetches three times higher price than desi cultivars. Although India is the largest producer, it imports chickpea from Australia, Canada, Mexico, Turkey, Ethiopia, etc., to cater the need of ever-growing population. Similarly, Spain also needs to import approximately double than the Spanish chickpea production (FAO 2010). This is because of low productivity ( $<1$ tons per hectare) as a result of exposure of the crop to a number of abiotic stresses such as drought, salinity, and biotic stresses (e.g., Fusarium wilt (FW) and Ascochyta blight (AB)).

\subsection{Need for Draft Genome Sequence}

Increasing and stabilizing the seed yield while minimizing inputs is the major aim of chickpea breeding. This goal can be achieved by developing cultivars better adapted to stresses in local environments. The recent developments in high-throughput or next-generation sequencing (NGS) technologies are opening up a wealth of possibilities for pulse breeding. A reference chickpea genome sequence provides a foundational resource for this important crop which also possesses a relatively modest genome size ( $\sim 740 \mathrm{Mb}$ ). Availability of genome sequence information will dramatically accelerate complete identification of genomic variations as it is easy to generate re-sequence data from different genotypes which can be aligned with the reference genome and then be linked with phenotypes, to obtain biological insights as well as for breeding applications. In addition, the reference genome will aid in elucidation of complex genetic interactions in chickpea, which in turn facilitates pulse geneticists and breeders to develop a full understanding of the variations found in each genotype. Analyses beyond sequencing include finding candidate gene(s), variation for traits related to nutritional quality, bioactive compounds and bioavailable micronutrients in chickpea, will enable integration of these outputs into the applied pulse breeding activities like (a) selection of parents for crossing, (b) screening the early generations for the desired genotypes that contain all (or the majority of) favorable alleles, and (c) integration of the selected lines into elite cultivar development.

This chapter summarizes the background history of two independent efforts to generate draft genome sequence of kabuli and desi chickpea genomes. International Chickpea Genome Sequencing Consortium (ICGSC) was led by ICRISAT to decode the draft genome of kabuli genotype CDC Frontier, while The Next Generation Challenge Programme on Chickpea Genomics (NGCPCG) unraveled the genome sequence of desi genotype ICC 4958.

\subsection{ICGSC Efforts to Unravel Draft Genome Sequence of CDC Frontier Genotype}

Discussions initiated during the 5th International Conference on Legume Genetics and Genomics (ICLGG), held during July 8-10, 2010 in Asilomar, USA, led to the development of one consortium named as "International Chickpea Genome Sequencing Consortium (ICGSC)" co-led by ICRISAT, UC-Davis and BGI-Shenzhen, with the main objective of decoding the genome sequence information and making it available to chickpea research community. ICGSC comprised of seven leading research institutes of the world that have extensive expertise in both basic as well as applied genomics of chickpea. 
CDC Frontier, a high yielding medium seeded kabuli chickpea variety was selected for developing the genome sequence. This variety was developed at University of Saskatchewan, Canada from the cross FLIP 91-22C $\times$ ICC 14912 in 1993. While FLIP91-22C was developed by the International Center for Agricultural Research in the Dry Areas (ICARDA), in Aleppo, Syria, and ICC 14912 was developed by the ICRISAT, India.

\subsection{Consortium Partners and Strengths}

ICRISAT with a global mandate to improve chickpea crop has lead the efforts of unraveling the draft genome of chickpea. For $>40$ years, ICRISAT has been engaged in pre-breeding research and has been sharing the breeding lines with national partners for their evaluation and release of the varieties in the targeted zones/countries. ICRISAT, in collaboration with its partners developed significant amount of genetic and genomic resources as given in Tables 9.1 and 9.2. For instance, large-scale SSR markers, SNP markers, DArT markers, several inter- and intra-specific genetic maps and QTL maps have been developed. ICRISAT has developed genome-wide physical map of chickpea in collaboration with UC-Davis and National Institute of Plant Genome Research (NIPGR), India (Varshney et al. 2013). The ICRISAT genebank has the largest collection of 20,267 accessions in genus Cicer from 60 distinct countries across five continents (Asia, Africa, Americas, Europe, and Oceania-pacific) including 308 accessions of 18 (eight annual and ten perennial) wild Cicer species.

University of California, Davis, USA - The research group led by Douglas Cook, possessed extensive expertise in the areas of comparative and structural genomics of the legume family and transcriptional profiling. They have a special focus to understand the molecular and genetic basis of symbiotic nitrogen fixation and legumepathogen interactions. Apart from this, UC-Davis in collaboration with ICRISAT under Phase I of
Tropical Legumes I, funded by Bill and Melinda Gates Foundation contributed to develop numerous SNPs (based on Sanger, 454 and Solexa re-sequencing, as well as an Illumina SNP GoldenGate platform); large collections ( 2800) of SSRs; bacterial artificial chromosome (BAC) libraries and $>30 \mathrm{Mbp}$ of BAC-end sequence information at NCBI; a comprehensive inventory of $>400$ NBS-LRR disease resistance genes.

BGI-Shenzhen, China is a premier genomics research organization, with a goal for developing projects and platforms that are on the cutting edge of research and technologies. Further, they focus on developing all kinds of applications, including de novo sequencing and assembly of plant and animal genomes, large-scale genome re-sequencing, genetic association studies, gene expression profiling, whole transcriptome assembly, miRNA detection, ChIP-Seq studies, DNA methylation characterization and metagenomics.

University of Saskatchewan, Canada - The Crop Development Centre (CDC) at University of Saskatchewan developed more than 15 kabuli and desi varieties that have been released in Canada. In addition, several cultivars of specific market classes such as green and black desi and green cotyledon kabuli have been released. University of Saskatchewan has a breeding program that focuses on enhancing yield, resistance to $\mathrm{AB}$, earliness, grain visual, and processing qualities. Steady gains in yield potential together with the improvement in resistance to $\mathrm{AB}$ have been achieved over the past decade. Many recently released cultivars yield up to $20 \%$ or more than those that were released in mid-1990s. Molecular breeding efforts to develop improved genotypes for $\mathrm{AB}$ are underway (Tar'an et al. 2007a, b). Seed qualities like seed size, shape, and seed coat color were main focus and have been working in collaboration with ICRISAT, France and Australia for developing inter-specific hybrids in chickpea. In terms of genomics research, identified several SNPs from 454 sequencing of various tissues of CDC Frontier. The CDC chickpea breeding program has developed a number of populations to facilitate studying of $\mathrm{AB}$ blight disease resistance and others in chickpea (Table 9.3). 
Table 1 Genetic resources developed at ICRISAT

\begin{tabular}{|c|c|c|c|}
\hline Cross & Generation & No. of RILs & Segregating traits/significance \\
\hline \multicolumn{4}{|l|}{ Mapping populations } \\
\hline ICC $4958 \times$ ICC 1882 & $\mathrm{~F}_{10+}$ & 264 & Root traits \\
\hline ICC $283 \times$ ICC 8261 & $\mathrm{~F}_{10+}$ & 281 & Root traits \\
\hline Annigeri $\times$ ICC 4958 & $\mathrm{~F}_{10+}$ & 257 & Root traits \\
\hline ICCV $2 \times$ JG 11 & $\mathrm{~F}_{3}$ & 290 & Salinity tolerance \\
\hline ICC $6263 \times$ ICC 1431 & $\mathrm{~F}_{6}$ & 286 & Salinity tolerance \\
\hline ICC 506-EB × Vijay & $\mathrm{F}_{9}$ & 328 & Helicoverpa resistance \\
\hline ICC $3137 \times$ IG 72953 & $\mathrm{~F}_{5}$ & 244 & Helicoverpa resistance \\
\hline ICC $3137 \times$ IG 72933 & & & Helicoverpa resistance \\
\hline $\mathrm{ICCV} 2 \times \mathrm{JG} 62$ & $\mathrm{~F}_{10+}$ & 573 & $\begin{array}{l}\text { Fusarium wilt resistance, Botrytis gray mold } \\
\text { resistance, Helicoverpa resistance and salinity tolerance }\end{array}$ \\
\hline WR $315 \times$ C104 & $\mathrm{F}_{10+}$ & 84 & Fusarium wilt resistance \\
\hline ICCV $2 \times$ ICC 1496 & $\mathrm{~F}_{8}$ & 249 & Botrytis gray mold resistance \\
\hline ICCV $10 \times$ ICC 1496 & $\mathrm{~F}_{8}$ & 250 & Botrytis gray mold resistance \\
\hline $\mathrm{Pb} 7 \times \mathrm{ICCV} 04516$ & $\mathrm{~F}_{4}$ & 281 & Ascochyta blight resistance \\
\hline ICC $995 \times$ ICC 5912 & $\mathrm{~F}_{6}$ & 246 & Protein content \\
\hline \multicolumn{4}{|l|}{$M A B C$ populations } \\
\hline JG $11 \times$ ICC 4958 & $\mathrm{BC}_{3} \mathrm{~F}_{2}$ & & For enhancing drought tolerance \\
\hline ICC $92318 \times$ ICC 8261 & $\mathrm{BC}_{3} \mathrm{~F}_{2}$ & & For enhancing drought tolerance \\
\hline KAK $2 \times$ ICC 8261 & $\mathrm{BC}_{3} \mathrm{~F}_{2}$ & & For enhancing drought tolerance \\
\hline \multicolumn{4}{|l|}{ MARS populations } \\
\hline JG $11 \times$ ICCV 04112 & $\mathrm{~F}_{5}$ & 188 & For accumulation of favorable alleles for drought tolerance \\
\hline JG $130 \times$ ICCV05107 & $\mathrm{F}_{5}$ & 188 & For accumulation of favorable alleles for drought tolerance \\
\hline
\end{tabular}

Table 2 Genomic resources developed by ICRISAT and its partners

\begin{tabular}{|c|c|c|c|}
\hline \multicolumn{3}{|l|}{ Marker resources } & \multirow[t]{2}{*}{ Transcriptomic resources } \\
\hline SSRs & SNPs & DArT & \\
\hline $\begin{array}{l}311 \text { from SSR-enriched library (in } \\
\text { collaboration with University of } \\
\text { Frankfurt, Germany); } 1344 \text { from } \\
\text { BAC-end sequences (in } \\
\text { collaboration with UC-Davis, USA) }\end{array}$ & $\begin{array}{l}\text { 9,000 identified and } 768 \text { on } \\
\text { GoldenGate assay (in } \\
\text { collaboration with UC-Davis, } \\
\text { USA, NCGR, USA) }\end{array}$ & $\begin{array}{l}\text { Ca. } 5,000 \\
\text { extended array } \\
\text { with } 15,360 \\
\text { (in } \\
\text { collaboration } \\
\text { with DArT Pty } \\
\text { Ltd, Australia) }\end{array}$ & $\begin{array}{l}\text { 20,665 Sanger ESTs; } \\
\text { 435,018 454/FLX reads; } \\
\text { 103,215 TUSs; and } \\
\sim 118 \text { million Solexa } \\
\text { reads (in collaboration } \\
\text { with NCGR, USA and } \\
\text { UC-Davis, USA) }\end{array}$ \\
\hline
\end{tabular}


Table 3 RIL populations and polymorphic traits available at University of Saskatchewan

\begin{tabular}{l|l|l}
\hline Cross & Polymorphic traits/markers ${ }^{\mathrm{a}}$ & Reference \\
\hline ILC $72 \times \mathrm{Cr} 5-10$ & $\begin{array}{l}\text { Blight, B/b, Tt, Hg, Isoenz, cross-genome markers, ISSR, RAPD, } \\
\text { STMS }\end{array}$ & Cobos et al. (2006) \\
\hline $\begin{array}{l}\text { ICCL } 81001 \times \mathrm{Cr} \\
5-9\end{array}$ & B/b, Fs, FOC5, Hg, Rt, Df, ISSR, RAPD, STMS & Cobos et al. (2009) \\
\hline $\begin{array}{l}\text { ILC } \\
3279 \times \text { WR315; } \\
\text { WR } 315 \times \text { ILC } \\
3279\end{array}$ & Blight, B, FOC5, RAPD, SCAR, STMS & Iruela et al. (2006, \\
\hline CA $2139 \times$ JG 62 & B/b, Tt, Sfl, FOC0, ISSR, RAPD, STMS & 2007) \\
\hline CA2156 $\times$ JG62 & $B / b, T t, S f l, F O C 0, I S S R, R A P D, S T M S$ & $\begin{array}{l}\text { Cobos et al. (2005, } \\
\text { 2007) } \\
\text { Halila et al. (2009) }\end{array}$ \\
\hline
\end{tabular}

${ }^{\mathrm{a}} F O C$ Fusarium wilt resistance genes; $B$ flower color (pink/white); $f$ days to flower $g 100$ seed weight; $G h$ Growth habit; $L S$ length of the seed; SC seed color; Sfl and $s$ : single/double pod; STC stem color; $T t$ testa thickness

CSIRO/University of Western Australia/ Curtin University, Australia-Dr. Karam Singh's group had world leading expertise on biotic stresses in legumes and highly relevant expertise on crop and patho-genomics. The Australian group has made excellent use of the model legume Medicago truncatula to progress legume disease and pest research. Of high relevance to this effort is their expertise on the major fungal pathogens of chickpea worldwide namely Ascochyta rabiei and Fusarium oxysporum. In the case of $A$. rabiei, they have generated a genome sequence using NGS technology involving Illumina $75 \mathrm{bp}$ paired-ends reads at $\sim 23 \mathrm{X}$ coverage and have identified $\sim 12,000$ protein encoding genes. In the case of $F$. oxysporum, they have generated the sequence of a medic isolate again using NGS technology. This group also has excellent expertise on another economically important soil-borne fungal pathogen, Rhizoctonia solani, which is an important problem for chickpea. They identified key transcriptional regulators in $M$. truncatula that can give high levels of resistance to $R$. solani when overexpressed in the roots of composite plants without any deleterious effects on plant growth (Anderson et al. 2010).

University of Córdoba/IFAPA, Spain - The research group in Córdoba (IFAPA and Univ. of Córdoba, Spain) has been running plant breeding programmes focused in obtaining new cultivars, better adapted to Mediterranean conditions together with the quality required in Spanish market. Integration of marker-assisted selection (MAS) in traditional breeding programs accelerates the achievement of productive cultivars. Involved in chickpea map development (Millán et al. 2010) but still it is necessary to target some agronomic traits or saturate genomic areas in order to have useful makers for MAS. Development of trait-specific germplasm for instance, recent development of near isogenic lines (NILs) differing in resistance for FW could facilitate the identification of different genes (Castro et al. 2010) and race-specific resistance to $F$. oxysporum. The most significant QTLs involved in $\mathrm{AB}$ resistance are two genomic regions in LG4 enclose two clearly differentiated QTLs (QTL1 and QTL2) more than $30 \mathrm{cM}$ apart. Efforts to find candidate genes for QTL1 and QTL2 have been attempted (Iruela et al. 2009). Other traits like bushy growth habit and double-podded mutation also have a positive effect on yield and yield stability in chickpea crop under Mediterranean conditions (Rubio et al. 1998, 2004). Both traits are controlled by a single gene: simple/double pod ( $S / s$ or $S f / s f l)$ and erect/bushy habit $(G h / g h)$ (Muehlbauer and Singh 1987).

National Centre for Genome Resources (NCGR), Santa Fe, USA has a worldwide 
reputation for sequencing and the development of custom bioinformatic resources for research communities. The NCGR Sequencing Center undertakes massively parallel sequencing services using Illumina ${ }^{\circledR}$ (Solexa) Genome Analyzer and ABI SOLiD4 instruments and also provides genotyping, the gold standard for high-throughput SNP screening, and supplies software tools and services for analysis of genome and transcriptome projects worldwide. NCGR contributed to informatics and data analysis of chickpea genome sequences data.

Above-mentioned institutes were the part of ICGSGC (http://ceg.icrisat.org/gt-bt/ICGGC/ ICGSC.htm). The key scientists from each institute leveraged resources from various funding organization including the CGIAR Generation Challenge Programme (GCP), US National Science Foundation (NSF), Saskatchewan Pulse Growers (Canada), Grains Research \& Development Corporation (Australia), Indo-German Science Technology Corporation (Germany and India), National Institute for Agricultural and Food Research and Technology (Spain), National Research Initiative of US Department of Agriculture's National Institute of Food and Agriculture (USA), Ministry of Education, Youth and Sports of the Czech Republic and the European Regional Development Fund, University of Cordoba, ICAR (India), BGI (China) and ICRISAT for decoding the genome sequence of chickpea.

\subsection{Efforts of NGCPCG to Unravel the Genome Sequence of ICC 4958 a Desi Genotype}

NGCPCG was initiated by a group of nine NIPGR scientists, with three main objectives: (1) Chickpea genome sequence analysis and its alignment to genetic map; (2) Functional genomics of stress tolerance in chickpea; (3) Functional genomics of chickpea seed development and nutrition. The NGCPCG is purely the work of scientists belonging to just one Indian institute, the NIPGR. The NGCPCG, apart from deciphering the genes, had also worked on finding markers distributed all over the genome which could be used by plant breeders for creation of better variety of chickpea. Complexity of the genome is very high, and it reflects on the nature of biological evolution that there has been more than one line of evolution. The chickpea cultivar ICC4958 was used for generating the draft genome.

\subsection{Announcement of Chickpea Genome}

Chickpea draft genome sequence decoded was published on January 27, 2013, in a high impact factor Journal "Nature Biotechnology." This was the result of global research partnership led by ICRISAT, involving 49 scientists from 23 organizations in 10 countries. This genome sequence breakthrough was announced by Mr. Ashish Bahuguna, the then Secretary, Department of Agriculture \& Cooperation, Dr. Swapan Datta, the then Deputy Director General, Crop Science, ICAR, Dr. William Dar, the then Director General, ICRISAT, and Dr. Rajeev K. Varshney, Coordinator, ICGSC on January 28, 2013 in Krishi Bhawan, New Delhi (Fig. 9.1).

During the press conference announcing the decoding of the chickpea genome sequence at Krishi Bhavan, New Delhi, the then Director General Dr. Dar said, "In the face of growing global hunger and poverty amid the threat of climate change, the chickpea genome sequence will facilitate the development of superior varieties that will generate more income and help extricate vulnerable dryland communities out of poverty and hunger for good, particularly those in the drylands of Asia and sub-Africa for whom ICRISAT and our partners are working." In addition Mr. Ashish Bahuguna, the then Secretary, Ministry of Agriculture, Government of India, recognizing the efforts of the global research team, said, "Decoding of the chickpea genome would facilitate the development of 


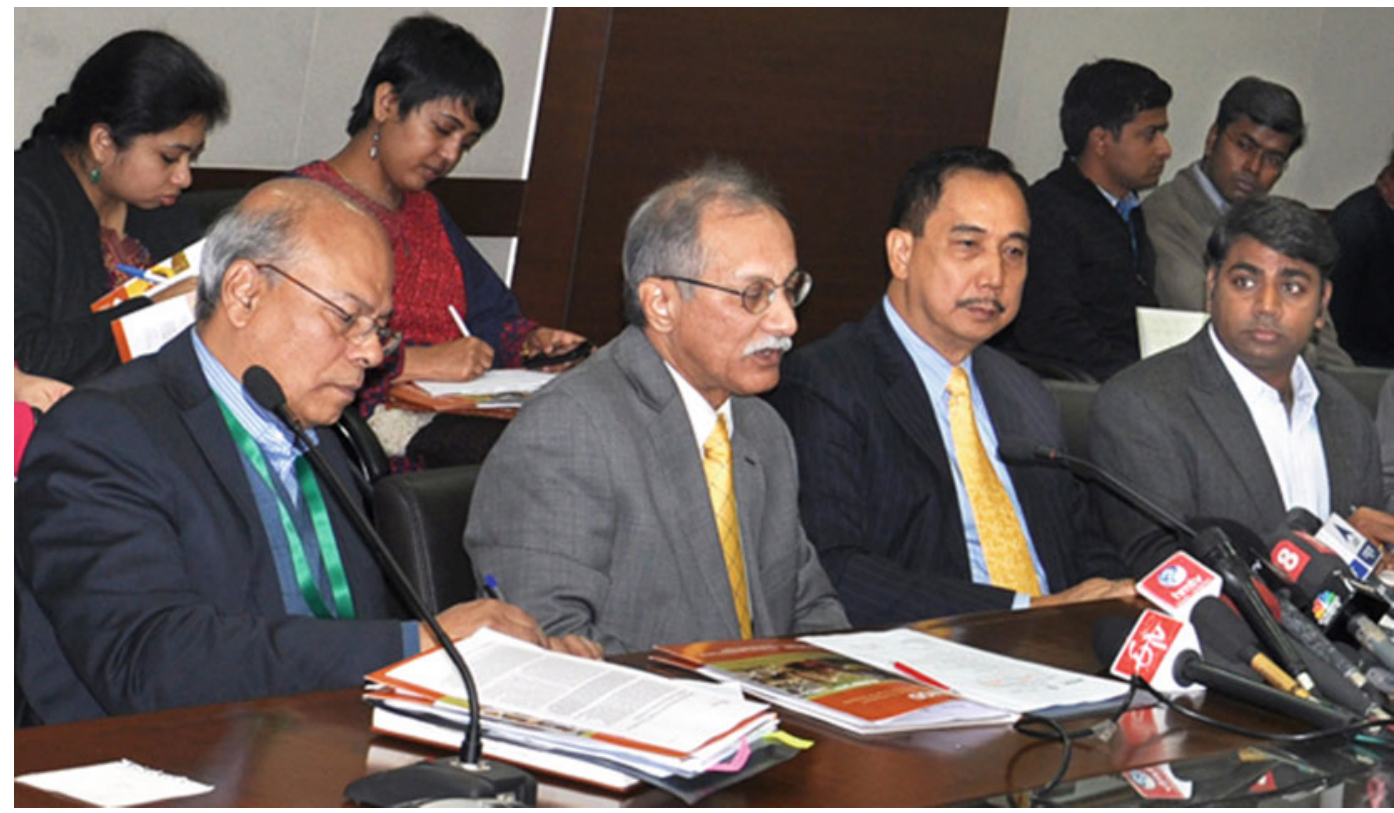

Fig. 1 (Left-Right) Dr. Swapan Datta, the then DDG (Crop Science), ICAR; Mr. Ashish Bahuguna, the then Secretary, Ministry of Agriculture, Government of India; Dr. William Dar, the then Director General, ICRISAT; and

improved varieties with higher yields and greater tolerance to biotic and abiotic stresses. This would help chickpea farmers to increase productivity, reduce cost of inputs, and realize higher incomes." He added: "This development is of great importance to India, the largest producer and consumer of chickpea." Dr. Swapan Datta, the then Deputy Director General-Crop Science, Indian Council of Agricultural Research (ICAR), highlighted that "The chickpea genome sequence is expected to help in the development of superior varieties with enhanced tolerance to drought and resistance to several biotic stresses. India will benefit most from this genome sequence, our country being the largest producer of chickpea. This, in my opinion, is by far the most significant collaboration between ICAR, ICRISAT, and the global genomics community." While addressing the addressing the media during the press conference Dr. Rajeev K. Varshney, mentioned that
Dr. Rajeev K. Varshney, coordinator of ICGSC and Director-Center of Excellence in Genomics, ICRISAT during the press conference announcing the decoding of the chickpea genome sequence at Krishi Bhavan, New Delhi

"Genetic diversity, an important prerequisite for crop improvement, is very limited and has been a serious constraint for chickpea improvement. This study will provide not only access to "good genes" to speed up breeding but also to genomic regions that will bring genetic diversity back from landraces or wild species to breeding lines. Currently, it takes 4-8 years to breed a new chickpea variety. This genome sequence could reduce by half the time to breed for a new variety with market-preferred traits." Prof. MS Swaminathan, Member of Indian Parliament and renowned agricultural scientist said, "I would like to compliment the excellent scientific work done by Rajeev K. Varshney of ICRISAT and his colleagues in developing a high-quality genome sequence of chickpea. I am confident that the knowledge provided by this study will help accelerate the improvement of this crop through marker-assisted breeding." 


\subsection{A Road Map for Chickpea Improvement}

Genome sequence will play a crucial role in speeding up the development of improved varieties that will ensure the food and nutritional security and enhance the income for small holder farmers. In addition, genome sequence also provides the basis for a wide range of studies, from the important goal of accelerated breeding to identifying the molecular basis of key agronomic traits, in addition to understanding the basic legume biology. In addition to developing superior varieties tolerant to drought, heat, Fusarium wilt and Ascochyta blight, genome sequence can also be used to develop early maturing varieties as well as varieties amenable for mechanical harvesting so that chickpea varieties can be introduced to new niches and drudgery of women can also be reduced. This would help chickpea farmers to increase productivity, reduce cost of inputs and realize higher incomes. Based on the discussions with higher officials and extensive consultations with stakeholders, a road map was developed for enhancing chickpea productivity in India.

For utilizing the genome sequence information of chickpea, Department of Agriculture and Cooperation, Ministry of Agriculture, Government of India funded a project entitled "Utilizing chickpea genome sequence for crop improvement" to a consortium of leading chickpea breeders and genomics scientists from different institutes like ICRISAT, ICARDA-New Delhi, Indian Institute of Pulses Research (IIPR) Kanpur, Rajmata Vijayaraje Scindia Krishi Vishwa Vidyalaya (RVSKVV), RAK College of Agriculture (RAKCA), Sehore, MP, India, and Rajasthan Agricultural Research Institute (RARI) -Durgapura, Junagadh Agricultural University (JAU)_Junagadh. This project had a major emphasis on (i) identification of superior lines, (ii) integrate genomic selection (GS) approach in chickpea breeding, (iii) identification of molecular markers associated with trait of interest for chickpea using nested association mapping (NAM) and linkage mapping approach, and (iv) mapping of targeted traits and harnessing the germplasm diversity using genome-wide association study (GWAS) approach. Similarly, Indo-Australian Biotechnology Fund (IABF) and Department of Biotechnology, Government of India jointly funded a project entitled "Improving Chickpea Adaptation to Environmental Challenges in Australia and India." This proposal is a collaboration between ICRISAT, Indian Agricultural Research Institute (IARI), India, South Australian Research and Development Institute, Australia, and The University of Western Australia, Australia. The project has a major focus on identification and delivering genetic improvements in chickpea that will support breeding for enhanced abiotic and biotic stress.

\subsection{Conclusion}

In the year 2010, ICGSGC came into existence with main objective of decoding the chickpea genome sequence, and as a result of efforts of the consortium, the genome sequence was made public in 2013. Ever since the genome sequence information is available to chickpea research community, there have been efforts to utilize this information for crop improvement. For instance, the funding organizations like Department of Agriculture and Cooperation, Ministry of Agriculture, Government of India, Indo-Australian Strategic Research Fund have already encouraged research groups that are making use of chickpea genome sequence and re-sequence information for developing the climate resilient chickpeas.

\section{References}

Anderson JP, Lichtenzveig J, Gleason C, Oliver RP, Singh KB (2010) The B-3 ethylene response factor MtERF1-1 mediates resistance to a subset of root pathogens in Medicago truncatula without adversely affecting symbiosis with rhizobia. Plant Physiol 154:861-873

Arumuganathan K, Earle ED (1991) Nuclear DNA content of some important plant species. Plant Mol Biol Rep 9:208-218

Castro P, Pistón F, Madrid E, Millán T, Gil J, Rubio J (2010) Development of chickpea near-isogenic lines for fusarium wilt. Theor Appl Genet 121:1519-1526 
Cobos MJ, Fernández MJ, Rubio J, Kharrat M, Moreno MT, Gil J, Millán T (2005) A linkage map of chickpea (Cicer arietinum L.) based on populations from kabuli $\times$ desi crosses: location of genes for resistance to fusarium wilt race 0 . Theor Appl Genet 110:1347-1353

Cobos MJ, Rubio J, Strange RN, Moreno MT, Gil J, Millán T (2006) A new QTL for Ascochyta blight resistance in a RIL population derived from an intraspecific cross in chickpea. Euphytica 149:105111

Cobos MJ, Rubio J, Fernández-Romero MD, Garza R, Moreno MT, Millán T, Gil J (2007) Genetic analysis of seed size, yield and days to flowering in a chickpea RIL population derived from a kabuli $\times$ desi cross. Ann Appl Biol 151:33-42

Cobos MJ, Winter P, Cubero JI, Gil J, Millán T, Rubio J (2009) Genetic analysis of agronomic traits in a wide cross of chickpea. Field Crops Res 111:130-136

FAO (2010) http://faostat.fao.org/ Updated: 23 June 2009

FAO (2016) http://www.fao.org/faostat/en/\#data/QC. Accessed on 30 Sep 2016

Halila I, Cobos MJ, Rubio J, Millán T, Kharrat M, Marrakchi M, Gil J (2009) Tagging and mapping a second resistance gene for Fusarium wilt race 0 in chickpea. Eur J Plant Pathol 124:87-92

Iruela M, Rubio J, Barro F, Cubero JI, Millán T, Gil J (2006) Detection of two quantitative trait loci for resistance to ascochyta blight in an intra-specific cross of chickpea (Cicer arietinum L.): development of SCAR markers associated with resistance. Theor Appl Genet 112:278-287

Iruela M, Castro P, Rubio J, Cubero JI, Jacinto C, Millán T, Gil J (2007) Validation of a QTL for resistance to ascochyta blight linked to resistance to fusarium wilt race 5 in chickpea (Cicer arietinum L.). Eur J Plant Pathol 119:20-37

Iruela M, Pistón F, Cubero JI, Millán T, Barro F, Gil J (2009) The marker SCK13603 associated with resistance to ascochyta blight in chickpea is located in a region of a putative retrotransposon. Plant Cell Repoter 28:53-60
Millán T, Winter P, Jüngling R, Gil J, Rubio J, Cho S, Cobos MJ, Iruela M, Rajesh PN, Tekeoglu M, Khal G, Muehlbauer FJ (2010) A consensus genetic map of chickpea (Cicer arietinum L.) based on 10 mapping populations. Euphytica 175:175-189

Muehlbauer FJ, Singh KB (1987) Genetic of chickpea. In: Saxena MC, Singh KB (eds) The Chickpea. CAB International, Wallingford, UK, pp 99-125

Rubio J, Moreno MT, Cubero JI, Gil J (1998) Effect of the gene for double pod in chickpea on yield, yield components and stability of yield. Plant Breed 117:585-587

Rubio J, Flores F, Moreno MT, Cubero JI, Gil J (2004) Effects of the erect/bushy habit, single/double pod and late/early flowering genes on yield and seed size and their stability in chickpea. Field Crops Res 90:255-262

Tar'an B, Warkentin TD, Tullu A, Vandenberg A (2007a) Genetic relationships among chickpea (Cicer arietinum L.) genotypes based on the SSRs at the quantitative trait loci for resistance to ascochyta blight. Eur J Plant Pathol 119:39-51

Tar'an B, Warkentin TD, Tullu A, Vandenberg A (2007b) Genetic mapping of ascochyta blight resistance in chickpea (Cicer arietinum L.) using simple sequence repeat linkage map. Genome 50:26-34

van der Maesen LJG (1987) Origin, history and taxonomy of chickpea. In: Saxena MC, Singh KB (eds) The chickpea. CAB Int, UK, pp 11-34

Varshney RK, Song C, Saxena RK, Azam S, Yu S, Sharpe A, Cannon S, Baek J, Rosen BD, Taran B, Millan T, Zhang X, Ramsay LD, Iwata A, Wang Y, Nelson W, Farmer AD, Gaur PM, Soderlund C, Penmetsa RV, Xu C, Bharti AK, He W, Winter P, Zhao S, Hane JK, Garcia NC, Condie JA, Upadhyaya HD, Luo MC, Thudi M, Gowda CLL, Singh NP, Lichtenzveig J, Gali KK, Rubio J, Nadarajan N, Dolezel J, Bansal KC, Xu X, Edwards D, Zhang G, Kahl G, Gil J, Singh KB, Datta SK, Jackson SA, Wang J, Cook DR (2013) Draft genome sequence of chickpea (Cicer arietinum) provides a resource for trait improvement. Nat Biotechnol 31:240-246 